Color Plates (Following page 344)

Jordan Belson: Phenomena

Jordan Belson: Samadhi and Momentum

John Whitney: Permutations

John Whitney: Permutations

John Whitney, Jr.: Images from triple-projection computer film

John Stehura: Cybernetik 5.3

Terry Riley and Arlo Acton: Music With Balls

Philip Makanna: The Empire of Things

James Seawright: Capriccio for TV

Nam June Paik: Three experiments with color cathode tube

Scott Bartlett: OFFON

Clouds of barium atoms ionized by solar radiation

\title{
Black-and-white Plates
}

Stan Brakhage: Dog Star Man 89

Will Hindle: Chinese Firedrill 94

Patrick O'Neill: 736298

John Schofill: XFilm 101

Ronald Nameth: Andy Warhol's Exploding Plastic Inevitable 104

Paul Morrissey: Flesh 118

Carolee Schneemann: Fuses 120

Michael Snow: Wavelength 123

Mystical alignment of planets and sun in 2001: A Space Odyssey 142

Starchild Embryo from 2001: A Space Odyssey 145

Stargate Corridor from 2001: A Space Odyssey 152

Slit-scan machine 155

Jordan Belson: Allures 161

Jordon Belson: Re-Entry 164

Jordan Belson: Re-Entry 165

Jordan Belson: Samadhi 170

Jordan Belson: Momentum 175

Stereo pairs from a film by A. Michael Noll 190

Mechanical analogue plotter (above); animated sequence (below) 195

Cybernetic movie studio 197

Reclining nude scanned and reconstructed by computer 201 
Charles Csuri: Hummingbird 202

Demonstration of RCA's liquid crystal display 204

John Whitney working with his mechanical analogue computer 209

Detail shots of mechanical analogue computer 211

John Whitney: Catalogue 212

Dr. Jack Citron of IBM Los Angeles 219

James Whitney: Lapis 224

James Whitney: Lapis 225

John Whitney, Jr.: Untitled 232

Michael Whitney: Binary Bit Patterns 235

The Whitney brothers 237

John Stehura: Cybernetik 5.3 240

Computer interpretation of the word "movies" 247

Variations of the Beflix technique 248

Peter Kamnitzer: City-Scape 251

The Picturephone 262

Use of Chroma-Key video matting 271

Use of two cameras and three VTRs 272

Composite scene from the Limbo program 273

Stan VanDerBeek at work 278

Disintegration of form in Videospace 286

Use of six levels of delayed videotape superimpositions 288

Loren Sears: Sorcery 290

Otto Piene: Electronic Light Ballet 300

Electromagnetic distortions of the video image by Nam June Paik 305

Nam June Paik with Charlotte Moorman in TV Bra for Living Sculpture 307

Aldo Tambellini: Black TV 309

Aldo Tambellini: Black Video Two 310

Aldo Tambellini in control room of WGBH-TV, Boston 312

Eric Siegel: Psychedelevision 315

Scott Bartlett: Moon 322

Tom DeWitt: The Leap 325

Scott Bartlett filming Tom DeWitt 327

Jud Yalkut: Paikpieces 329

The King of Sweden as seen in Monument 332

Paul McCartney in Monument 333

Lutz Becker: Horizon 335

Les Levine with Iris 338

Les Levine with Contact 341

Frank Gillette and Ira Schneider: Wipe Cycle 342 
Stan VanDerBeek with multifaceted surface 349

Stan VanDerBeek presides over intermedia presentation 350

Chamber One of Roman Kroitor's Labyrinthe at Expo '67 353

Chamber Three of Labyrinthe 354

Two scenes from Francis Thompson's We Are Young 355

The Diapolyceran Screen at Expo '67 356

The Diapolyceran Screen 357

Sensory-kinetic multi-media experience at Cerebrum $\quad 360$

Cerebrum, New York City 362

Carolee Schneemann: Night Crawlers 367

Carolee Schneemann: Illinois Central 372

Centers: A Ritual of Alignments performed by Milton Cohen 373

ONCE Group: Unmarked Interchange 375

Milton Cohen's Space Theatre 376

John Cage and Ronald Nameth: HPSCHD 377

Two scenes from Ronald Nameth's As the World Turns 379

Two scenes from Robert Whitman's Prune Flat 380

Aldo Tambellini: Black Zero 382

Aldo Tambellini and Otto Piene: Black Gate Cologne 384

Wolf Vostell: Electronic Happening Room 385

Henry Jacobs and Jordan Belson 388

Planetarium projector equipped for Vortex Concerts 390

Isobe's Floating Theatre at Oneonta, N.Y. 393

Two images from the lightworks of the Single Wing Turquoise Bird 395

Sequence of images from Circles 397

Diffusion of a laser beam 401

Multiple-exposure photo approximation of an animated hologram 402

Two photos from holographic movie of tropical fish 405

Schematic diagram of Hughes holographic movie system 405

Hughes holographic projection system 408

Holographic movie viewing system developed by North American Philips Corporation 409

Hemispherical mirror developed by Los Angeles chapter of Experiments in Art and Technology 417 
